Volume 4 | Issue 1

1994

\title{
Child Health: Equity in the Non-Industrialized Countries
}

Bonita Stanton

Follow this and additional works at: https://scholarlycommons.law.case.edu/healthmatrix

Part of the Health Law and Policy Commons

\section{Recommended Citation}

Bonita Stanton, Child Health: Equity in the Non-Industrialized Countries, 4 Health Matrix 41 (1994)

Available at: https://scholarlycommons.law.case.edu/healthmatrix/vol4/iss1/5

This Symposium is brought to you for free and open access by the Student Journals at Case Western Reserve University School of Law Scholarly Commons. It has been accepted for inclusion in Health Matrix: The Journal of Law-Medicine by an authorized administrator of Case Western Reserve University School of Law Scholarly Commons. 


\title{
CHILD HEALTH: EQUITY IN THE NON-INDUSTRIALIZED COUNTRIES $\dagger$
}

\author{
Bonita Stanton $\dagger^{\dagger}$ \\ INTRODUCTION
}

THE PAST FOUR DECADES have witnessed a substantial global effort to improve child survival. This effort has been accompanied by precipitous falls in infant and child mortality. Multiple reviews have noted these improvements and have delineated new strategies for continuation of this progress [1,2]. Simultaneously, considerable literature has developed in many of the higher income countries regarding inequity and maldistribution of resources and health outcomes between sub-populations [3,4]. By contrast, a relatively small literature has addressed the issue of equity at a global level.

Defining 'equity' in relation to child survival in non-industrialized countries is itself potentially a complex task [5]. Among many possibilities, equity can be defined from the perspective of access to health resources, whether potential (i.e. are the concentrations of health facilities equivalent for all subpopulations?) or real (i.e. are the socio-cultural barriers to access adequately compensated for, such that real access is equivalent between groups?). Alternatively, actual health outcomes may be posited as the ultimate yardstick by which to assess 'equity.' For purposes of this paper, the primary outcome of interest will employ the latter definition - equity in actual health outcomes. It is important to note that equity is an assessment of relative rather than absolute status. Thus, regardless of whether overall health outcomes are improving or deteri-

+ Reprinted in its entirety with permission from Elsevier Science Ltd., Pergamon Imprint, Oxford, England as it appeared in 38 Soc SCI MED 1375 (1994). Any electronic reproduction is strictly forbidden.

It Department of Pediatrics and the Center for Minority Health Research, University of Maryland, Baltimore, MD 21201, U.S.A. 
orating, the differences in health status between subpopulations may be decreasing, increasing or remaining static. It is the purpose of this paper to identify and characterize those groups who are not experiencing equity in health outcomes and to explore the reasons for this inequity and prospects for the future.

\section{GLOBAL TRENDS IN HEALTH OUTCOMES IN DEVELOPED AND DEVELOPING COUNTRIES}

There have been impressive decreases in infant and child mortality rates in recent decades. From 1950 to 1980 the infant mortality rate (IMR) decreased in Europe from 62 to 15 , in Latin America from 126 to 63, in Africa from 187 to 116 and in South Asia from 189 to 113 [6]. The median under-fives mortality rates (U5MRs) dropped from 299 to 199 in countries with the highest baseline mortality rates, and from 230 to 94 , from 121 to 36 and from 38 to 11 in those countries with high, moderate and low baseline mortality rates, respectively [7].

Concomitantly, significant improvements have been made in social development. Among the lowest income nations, adult literacy increased from 19 to $32 \%$ and female literacy from 8 to $19 \%$. The percentage of children enrolled in primary school likewise increased from 39 to $54 \%$. The ratio of females/males in school increased from $53 / 100$ to $74 / 100$ and in secondary schools from $39 / 100$ to $60 / 100$ [6,7]. From 1965 to 1986 the Gross National Product (GNP) increased in virtually all nonindustrialized countries [8].

\section{PATTERNS OF MORTALITY DECLINE: AN ISSUE IN EQUITY}

Global views of mortality declines are useful to represent overall trends. However, in an analysis of equity, it is the variations within and the deviations from this overall pattern of mortality decline that are of particular interest.

Table 1 depicts the data regarding global declines in mortality rates presented in the previous section. However, in addition to depicting the absolute decreases previously noted, the relative decrease is also presented. While the magnitude of the drop was the greatest among countries with the highest mortality rates - a $38 \%$ decline in Africa or a $36 \%$ decline in countries with U5MRs in the highest quartile - and greatest 
among countries with the lowest mortality rates - a $76 \%$ decline in Europe and a $72 \%$ decline among countries with U5MRs in the lowest quartile [6,7]. While in 1960 there was a 7.9-fold difference between the mortality rate of the highest and lowest quartiles, there is now a 17.5-fold difference. Thus, in spite of overall improvements in child mortality rates in the past few decades, equity in child survival between nations appears to have actually decreased rather than increased.

Table 1. International trends in under-fives mortality rate (U5MR)* among 129 nations by baseline mortality rate, $1960-1989 \dagger \dagger$

\begin{tabular}{lrrr}
\hline & \multicolumn{2}{c}{ U5MR } & \\
\cline { 2 - 3 } Baseline & 1960 & 1989 & \% Decline \\
mortality rate & 299 & 193 & 35 \\
\hline Very high $(N=38) \dagger$ & 230 & 94 & 59 \\
High $(N=31)$ & 121 & 36 & 70 \\
Middle $(N=28)$ & 38 & 11 & 71 \\
Low $(N=32)$ & &
\end{tabular}

*Deaths before age 5 per 1000 live births.

†Numbers of countries.

††Adapted from Ref. [7].

\section{SOURCES OF INEQUITY IN CHILD HEALTH OUTCOMES BETWEEN NATIONS}

There are several factors characterizing those nations who have not shared proportionately in recent global improvements in child health.

\section{Economic disparities}

First, there is a substantial disparity in economic resources between nations. As Shown in Table 2, there is a striking inverse correlation between child mortality rate and per capita GNP [7]. Likewise, the correlation between life expectancy and per capita GNP is high (Pearson $r=0.658$ ) [9]. 
Table 2. International under-fives mortality rate (U5MR)* among 129 nations by gross national product, 1989

Countries grouped

Median Median per capita

by baseline U5MR

U5MR gross national product

\begin{tabular}{lrr}
\hline Very high $(N=38) \dagger$ & 193 & $\$ 295$ \\
High $(N=31)$ & 94 & $\$ 830$ \\
Middle $(N=28)$ & 36 & $\$ 1725$ \\
Low $(N=32)$ & 11 & $\$ 12,575$ \\
\hline
\end{tabular}

*Deaths before age 5 per 1000 live births.

†Adapted from Ref. [7].

The absolute GNP is affected by resource allocation. For many of the least developed and middle income countries, spending on health has been difficult to sustain in view of limited resources and high debts. In 1987 among the 95 low and middle income countries, $1.1 \%$ of the gross domestic product was spent on health while $4.5 \%$ was spent on debt servicing [8].

Beyond absolute resource availability, inter-sectorial resource allocation also differs substantially by countries and appears to be strongly associated with child health outcomes. Thus, as might be anticipated, there is a nearly inverse relationship between percent government spending on health and U5MR, while there is a strong positive correlation between military spending and U5MR. Countries with higher government expenditure for health enjoy lower U5MR and those with higher expenditures for military suffer higher U5MR [7].

Clearly, economic factors are important determinants of differences in health outcomes between nations. However, there are other important determinants that can mediate or supersede these factors.

\section{Female Education}

There is a direct inverse relationship between national female literacy rate and national infant mortality rates. The association between female education and child survival has been one of the most robust findings across continents, nations, ethnic groups and socio-economic groups [10]. (For further elaboration of some of the hypothesized mechanisms of this effect, see section of 'Sources of Inequity Within Nations'.) 


\section{Urbanization}

In $198530 \%$ of the world's population resided in urban areas. By the year 2000 this number will reach $40 \%$ and by 2015 will surpass $50 \%$ [2]. Traditionally, urbanization is presented as having a positive influence on health outcomes [11]. An inverse relationship between mortality rates and percent of the population residing in urban areas is frequently cited as evidence of the beneficial effect of urbanization. Consistent with this view, in the 38 countries with the highest child mortality rates, only $28 \%$ of the population resides in urban areas. Forty-four and $55 \%$ of the population reside in urban areas in countries with high and mid-level U5MRs, respectively. By contrast, in countries with the lowest mortality rates, $77 \%$ of the population resides in urban areas [7].

These figures would seem to validate the hypothesis that urbanization is health-promoting. However, further analysis suggests that the relationship is probably not this simple. Among the countries with low U5MRs (primarily Europe and North America), the phenomenon of urbanization, of industrialization and of national wealth cannot readily be disentangled. As noted previously, child survival is substantially improved in those countries with the highest GNPs. Thus, in Europe and North America an examination of the association of the impact of urbanization on child health may in fact be an examination of the impact of economic prosperity.

But, urbanization is not necessarily synonymous with economic prosperity. Already there are large peri-urban settings in many countries with minimal industrialization and unemployment rates approaching $50 \%$ [12].

Possibly a more important investigation is the association between the process of urbanization and child survival. That is, for countries that are not yet 'successfully' industrialized who may or may not achieve this status for some years - what is the effect of the process of urbanization?

To assess the impact of the process of urbanization, the percent annual urban growth (rather than the total urban population), may be the proper analytic perspective. From this vantage a very different impact of urbanization emerges; a direct association such that with increasing annual rates of urbanization there is, in fact, a corresponding increase in child mortality. That is, those countries with very high U5MRs are 
witnessing a high (6\%) annual urban growth, those with intermediate U5MRs are experiencing a 3-4\% annual urban growth, and those with the lowest U5MRs have only a $1 \%$ annual urban growth [7].

These data are presented not to assess whether urbanization is 'good' or 'bad' for a nation. Rather, it is to underscore that urbanization is a remarkably complex process - one with multiple associations and impacts on survival, health and equity.

\section{SOURCES OF INEQUITY IN CHILD HEALTH OUTCOMES WITHIN NATIONS}

Just as global trends in infant and child survival may obscure important differences between nations, national trends may likewise obscure important differences within nations. As might be expected, many of the factors characterizing disenfranchised populations within nations are similar to those discussed as associated with poorer health outcomes between nations. However, two additional factors will also be discussed: race/ethnicity and gender.

\section{Economic Disparities}

Infant and childhood mortality rates are the highest among the poor in virtually all countries where this relationship has been examined, regardless of the overall wealth or poverty of the country. The effect in low income countries is exemplified in three states in India. In Uttar Pradesh, the infant mortality rate in the upper class was $109 / 1000$ while in the lower class it was 176 [13]. In the Punjab, it was 67 in the upper class and 117 in the lower [14]. In Rajasthan, corresponding rates were 186 and 331 [15]. Likewise, the effect is seen in middle income countries. In South Africa, the poorest quartile has an IMR of 40 while that of the wealthiest is 9, a 4.4-fold difference [16]. An abundant literature has confirmed this association in high income countries as well [17].

The sources of these universal differences are complex, resulting from differentials in access to (and use of) health-related facilities, exposure to environmental risks and understanding of preventive measures. 


\section{Race/ethnicity}

Like the racial disparities in health outcomes documented in the United States [3], ethnic, racial and tribal minorities experience substantial inequity in the non-industrialized countries. As an example, differences in key indicators between Blacks and Whites in South Africa are displayed in Table 3. Blacks experience an IMR of 80 compared to 12 for Whites. Sixteen percent of all African deaths will occur before one year of age compared to only $1 \%$ of all Caucasians deaths [18]. While the racial effect may be more pronounced in South Africa, most developing countries have their disenfranchised race, tribe or ethnic group who are experiencing substantially greater mortality rates than the population at large $[4,9]$.

Table 3. Basic health indicators for South Africa, 1987-1988

\begin{tabular}{llc}
\hline & Blacks & Whites \\
\hline Population & 29 million & 5 million \\
Infant mortality rate* & 80 & 12 \\
$\begin{array}{l}\text { Percent of all deaths occurring } \\
\text { before 1 year of age }\end{array}$ & 17 & 1 \\
$\begin{array}{l}\text { Percent of all deaths occurring } \\
\text { before 5 years of age }\end{array}$ & 24 & 2 \\
\hline
\end{tabular}

*Deaths before 12 months of age per 1000 live births.

Adapted from Ref. [8].

\section{Urbanization}

Data were presented in the previous section of this paper to indicate that at a global level the impact of urbanization on child health among the non-industrialized countries is not unequivocal. Similarly, within countries, the effect appears to be complex.

There is substantial evidence that urban areas enjoy lower rates of infant and child mortality. As illustrated in Table 4, the official IMR in most large cities in developing countries is substantially below that of the nation as a whole [6]. Likewise, in over $90 \%$ of lower and middle income countries, urban areas appreciate a higher concentration of health services and water [7]. 
Table 4. Urban infant mortality rate compared to national infant mortality rate in 5 developing countries, 1988

\begin{tabular}{lcc}
\hline & \multicolumn{2}{c}{ Infant mortality rate* } \\
\cline { 2 - 3 } & Urban & National \\
\hline Cairo; Egypt & 41 & 47 \\
Lagos; Nigeria & 21 & 90 \\
Bangkok; Thailand & 17 & 41 \\
Manila; Philippines & 32 & 45 \\
Karachi; Pakistan & 79 & 116 \\
\hline
\end{tabular}

*Deaths before 12 months of age per 1000 live births.

Adapted from Ref. [6].

However, these statistics (which appear to indicate a preferred status for urban rather than rural dwelling site) may not adequately represent the full picture.

First, a disproportionate percentage of the nation's wealthiest families reside in the urban areas; as such, per capita access to facilities and health indices will be fallaciously elevated for the population as a whole. The existence of such high technology facilities in no way ensures increased access to those with limited incomes and in fact may result in decreased access to primary health care [19].

Second, as these squatter settlements are frequently either illegal or at least 'informal', entire populations are not accounted for in government-sponsored census enumerations [20]. In countries such as Haiti [21], the IMR in urban slums appears to be substantially higher than the rural rate. Likewise, in Porto Allegre, Brazil, and Bombay, India, the mortality rate of slum dwellers was two- to threefold higher than that of the non-slum dweller [12].

Further, multiple studies worldwide have revealed that many morbidities, including diarrhea, parasites, nutrition and low birth weight, are higher in the slums than in the rural areas [22-26].

Finally, countries are, by and large, not planning prospectively but rather are reacting. Problems in sanitation and water supply, in housing, in day care provision and in infection control in group settings have not been entertained in most countries. When families migrate to an urban area it is only rarely because they have found great fortune. More commonly it is because they are driven by extreme poverty. Increasingly, 
women are seeking remunerative employment to meet family survival needs [27]. Elements inherent in 'urban' life itself may markedly impact on health or health seeking behavior. For example, work from Guatemala indicates that there is differential impact of wage labor on child rearing practices of urban vs rural women [28]. In rural areas women appear to have developed systems enabling them to engage in wage labor for up to 8 $\mathrm{hr}$. a day before they perceived a decreased in time spent in child care. By contrast, in urban areas, women report a decrease in time spent in child care after $1 \mathrm{hr}$. of wage labor. Health and water access systems which are possibly adequate for women who are engaged full-time in domestic tasks will not necessarily be adequate to meet the needs of women whose child rearing has been markedly impacted by wage earning.

\section{Female Education}

As the corollary to the robust association seen between female literacy and infant mortality between nations, maternal education is strongly correlated with child survival in virtually all local and national surveys where the association has been examined. Detailed analyses across socio-economic subgroups have established that maternal education functions as an independent factor, and not as a proxy for wealth [29].

The reasons for this association are complex and their investigation now constitutes an appreciable literature [29,30]. In addition to increasing an understanding of some of the determinants of health and disease, maternal education appears to be an empowering factor, enabling a woman to assess and access health resources potentially at her disposal. As well, enhanced educational level may grant a mother increased authority within her family and community, enabling her to seek health care for her children as she determines need [31].

\section{Gender}

Within certain countries, primarily Asia, after the perinatal period females experience a substantially higher mortality rate until mid-adulthood. Investigations of this phenomenon have revealed preferential feeding and increased access to health care for males [32]. 


\section{DISEASES RESPONSIBLE FOR INFANT AND CHILDHOOD MORTALITY}

Clearly, then, global equity in child health has not been achieved. Both at a national and local level, populations with certain identifying characteristics predictably have substantially elevated child mortality rates. An important next question concerns future prospects for equity among populations currently experiencing disproportionately high child mortality and morbidity. In order to address this question, it is logical to first review the profile of diseases and disease complexes associated with childhood mortality in the non-industrialized world. This discussion will underscore the changes in patterns of cause of death as mortality rates decline. That is, both between and within countries, populations with differing fatality rates exhibit differing cause of death patterns.

\section{Infancy (birth to 12 months)}

Figure 1 depicts changes in cause of death in infancy with differing baseline mortality rate [33]. Nutrition and measles, as causes of infant mortality, are greatest at 'high' mortality rates, decreasing substantially by both rate and percent as mortality rate drops. Deaths from acute respiratory infections and diarrhea actually increase (both relatively and absolutely) as mortality rates fall from the 'high' to the 'medium' level. However, with further declines in mortality rates, deaths due to diarrhea and respiratory diseases drop substantially. 
Child health
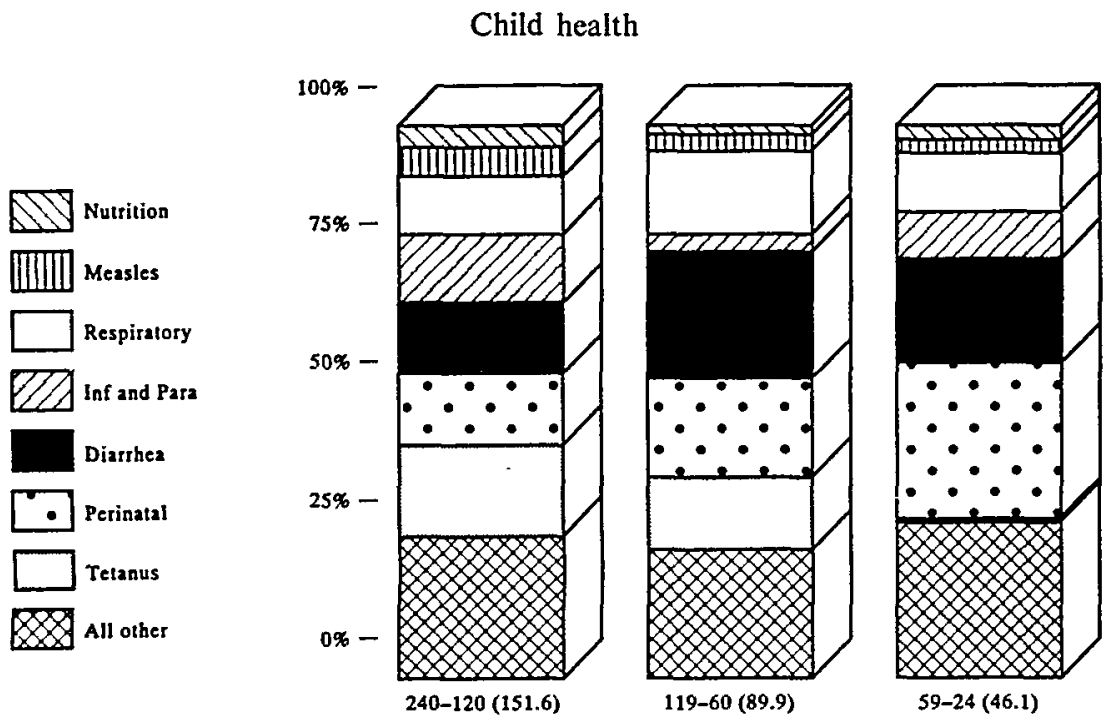

Decreasing infant mortality (average)

Fig. 1 Infant mortality profiles: cause of infant death at varying levels. (Taken from Ref. [33] with permission from Johns Hopkins Institute for International

Programs.)

The relative rate of perinatal deaths increases substantially with declining mortality rate, although the absolute rate remains essentially constant.

Neonatal tetanus deaths fall precipitously (both relatively and absolutely) with decreasing infant mortality rate, virtually disappearing at the 'low' level.

\section{Childhood (1-4 years)}

Likewise, the major categories of causes of early childhood death vary considerably in their contribution to mortality as mortality rates decline, as seen in Table 5 [18]. Populations have been grouped into four categories according to U5MR. [The data presented are from South Africa but are typical of the differences in causality of early childhood death (ages one through four) associated with changing mortality rates throughout the world.] 
Table 5. Percent cause of childhood death (ages 1-4) by under-fives mortality rate* South Africa, 1985

\begin{tabular}{|c|c|c|c|c|}
\hline \multirow[b]{3}{*}{ Disease category } & \multicolumn{4}{|c|}{ Underlying under-fives mortality rate } \\
\hline & $\begin{array}{c}\text { Very high } \\
(225)^{\dagger}\end{array}$ & $\begin{array}{l}\text { High } \\
(163)\end{array}$ & $\begin{array}{l}\text { Medium } \\
\text { (73) }\end{array}$ & $\begin{array}{l}\text { Low } \\
\text { (21) }\end{array}$ \\
\hline & \multicolumn{4}{|c|}{ Percent deaths among children aged $1-4$} \\
\hline Diarrhea & 26 & 29 & 13 & 3 \\
\hline Acute respiratory infection & 16 & 18 & 13 & 11 \\
\hline Malnutrition & 10 & 8 & 0 & 0 \\
\hline Trauma & 8 & 14 & 22 & 49 \\
\hline Other & 37 & 37 & 50 & 33 \\
\hline
\end{tabular}

*Deaths before age 5 per 1000 live births.

† Mean rate for population group.

Adapted from Ref. [18].

Diarrhea and acute respiratory infections are important causes in 'very high' U5MR populations. As was the case for infant mortality, initially as childhood mortality rates begin to decline, the contribution of diarrhea and respiratory infections actually increases. With further declines, their contribution also declines, becoming quite negligible for diarrhea in the low mortality rate populations.

Malnutrition is a major cause of death in 'high' mortality populations, but virtually disappears at 'low' rates.

The relative role of trauma increases steadily as mortality rate falls, accounting for nearly half among low mortality rate populations.

\section{CHANGE IN THE VELOCITY OF DECLINE AS A FUNCTION OF DIFFERING MORTALITY RATES IN DEVELOPING COUNTRIES}

It is reasonable to postulate that changes in mortality rate result at least in part from health, economic and political interventions or 'effort' or cost. The previous section established that as a population's infant and childhood mortality rates change, the diseases contributing to mortality also change. Therefore, it is reasonable to further postulate that the nature and level of 'effort' will also change as the mortality rate declines.

To examine this issue of effort, D'Souza [36] analyzed trends in past and projected mortality rates by quinquennia for Africa, including the percent decline between adjacent quin- 
quennia. He further calculated the 'effort' (manpower, infrastructure, etc.) required to bring about these changes. There has been a steady decline in IMR, beginning at 184 in 1950 and projected to be at 49 by 2020 . However, with decreasing IMRs, the percent decline has also decreased,beginning with a $12 \%$ decrease between quinquennia when the mortality rates were in the range of 180 to 170 , and projected to be only a $6 \%$ decrease when the IMR reaches 50 to 40 . Concomitantly, there has been a steady increase in the 'effort' required to bring about these smaller decreases. Thus, D'Souza estimates that the effort to bring about a reduction of IMR from 50 to 40 will approx. 1.5-fold higher than the effort required to bring about a reduction from 180 to 170 . That is, in Africa, as mortality rates have decreased, there has been a decrease in the velocity of the further declines and a corresponding increase in the "effort' required to bring about these changes.

This trend is not what would have been expected given the data presented in Table 1. Table 1 demonstrates that the greatest percent decline in mortality has been seen in those countries with the lowest absolute baseline mortality rates. Thus, the logical conclusion from this table would have been that as populations experience declining mortality rates, the rate of subsequent decline accelerates. However, what is instead being seen in Africa - and perhaps in other non-industrialized areas - is that as lower mortality rates are achieved, there is a decrease in the velocity of subsequent decline.

What is the difference? Why does there appear to be such a different pattern in changes in velocity of mortality rate between industrialized and non-industrialized countries?

Table 6 depicts the central government expenditures for health in countries grouped by income from 1972 to 1983 . Two features are of potential concern regarding the prospects for sustained improvements in childhood mortality rates among the poorer nations. First, while it might have been expected that the absolute health care costs would be greater in the industrialized countries, the relative (percent) contribution is also substantially greater among the industrialized countries - those with the lowest IMR and those with rates experiencing the greatest relative decline. Thus, in the low income countries the median percent allocation for health in 1983 was 2.7, while for the higher income countries it was 11.2. Moreover, among both the lowest and middle economy countries, the percent of cen- 
tral government funds expended on health declined from 1973 to 1983 , but actually increased among the high income countries [8].

Table 6. Central government expenditure for health by low, middle and high income countries, 1972-1983

\begin{tabular}{lccc}
\hline & \multicolumn{3}{c}{$\begin{array}{c}\text { \% Gross national products } \\
\text { allocated for health }\end{array}$} \\
\cline { 3 - 4 } & $\begin{array}{c}\text { gross national } \\
\text { product }\end{array}$ & 1972 & 1983 \\
\cline { 3 - 4 } Low-income countries & $\$ 260$ & 4.6 & 2.7 \\
Middle-income countries & $\$ 1250$ & 6.3 & 4.5 \\
High-income countries & $\$ 11,430$ & 10.0 & 11.2 \\
\hline
\end{tabular}

Adapted from Ref. [8].

Examination of the need for increased resources

Both these expenditure trends and the 'effort' analyses [36] discussed above, suggest that increasing resources are needed to bring about further improvements in health outcomes as mortality rates decline. A logical corollary of this hypothesis would be: as mortality rates decline, poor nations - and poor populations within these nations - may not have the incremental resources to effect further declines.

Table 7 illustrates the level of inputs required to effect mortality reductions through prevention or treatment of three major causes of infant and childhood mortality in populations with high mortality rates (tetanus, diarrhea and acute respiratory infections $[\mathrm{ARI}]$ ). (For more detailed tables and explanations see Refs [37,38].) 
Table 7. Summary of key inputs required to address priority diseases in populations with high infant and child mortality rates

\begin{tabular}{lll} 
& Prevention & Treatment \\
\hline Diarrhea & & \\
Facility & None-Low & Low \\
Personnel & Low & Low \\
Technology & Low & Low \\
Nursing & None & Variable \\
Intersector. Collab. Required? & No & \\
ARI & & \\
Facility & None-Low & Low \\
Personnel & Low & Low \\
Technology & Low & Low \\
Nursing & None & Low \\
Intersector. Collab. Required? & No & \\
& & \\
Tetanus & & Moderate \\
Facility & Low & High \\
Personnel & Low & High \\
Technology & Low & High \\
Nursing & None & \\
Intersector. Collab. Required? & No & \\
\hline
\end{tabular}

Adapted from Ref. [38].

This table illustrates several relevant points. First, for most of the diseases contributing substantially to mortality in high mortality populations, there are efficacious prevention options which have low requirements for facilities, personnel, technology and nursing. Inter-sectorial collaborations - (i.e. between the Ministries of Industry and Health) - are not essential for these intervention efforts.

Likewise, for two of the diseases (diarrhea and acute respiratory infection), treatment of most cases can be achieved with relatively low inputs in terms of facilities, personnel, technology and nursing.

By way of contrast, Table 8 depicts three illustrative conditions contributing substantially to mortality in low mortality rate populations (e.g. perinatal conditions) and trauma. There are striking differences regarding resources required for control of these disorders. 
Table 8. Summary of key inputs required to address priority diseases in populations with low infant and child mortality rates

\begin{tabular}{|c|c|c|}
\hline & Prevention & Treatment \\
\hline \multicolumn{3}{|l|}{ Perinatal diseases } \\
\hline Facility & Low & Moderate \\
\hline Personnel & Low & Moderate to High \\
\hline Technology & Low & Moderate \\
\hline Nursing & None & Moderate \\
\hline Intersector. Collab. Required? & Yes & \\
\hline \multicolumn{3}{|l|}{ Trauma } \\
\hline Facility & Low & Variable \\
\hline Personnel & Low & Variable \\
\hline Technology & Low & Variable \\
\hline Nursing & None & Variable \\
\hline Intersector. Collab. Required? & Yes & \\
\hline
\end{tabular}

Adapted from Ref. [38].

First, there are some effective prevention options which require relatively low inputs. However, these efforts would generally require substantial inter-sectorial collaboration. [For example, for prevention of perinatal conditions such as low birth weight, collaboration might be needed between the Ministries of Agriculture, of Health and of Industry (tobacco).]

Treatment requirements which are effective for the majority of cases do exist, but generally require substantial inputs in terms of facilities, personnel, technology and nursing - ranging from moderate to very high. (Note that there are no 'low' requirements.)

Clearly, then, the interventions which are effective against the major causes of mortality in lower mortality rate populations (i.e. perinatal diseases) do require more complex and costly interventions than those for higher mortality rate populations (i.e. diarrhea and ARI). Prevention options are available but may be difficult to implement.

\section{EMERGING PROBLEMS: ACQUIRED IMMUNODEFICIENCY SYNDROME (AIDS)}

Any discussion of equity in child health among the nonindustrialized countries must include the pandemic of AIDS. Impact on mortality 
Approximately ten million persons globally are believed to be infected with the human immunodeficiency virus. Three million of the infected are women and 500,000 are infants and children. The vast majority of these individuals live in non-industrialized countries.

In the next decade an estimated three million women and 2.7 million children will die from AIDS. In many cities, mostly in non-industrialized countries, sero-prevalence already exceeds $10 \%$ [39]. HIV infection is projected to have a substantial impact on the U5MRs in non-industrialized countries. For example, the United Nation's projected 1999 U5MR for subSaharan Africa in the absence of the AIDS epidemic was 132. As a result of the AIDS epidemic, the revised projection for these same countries is $159-189$, an increase of 21 to $43 \%$ [40].

\section{Prevention and treatment options}

Table 9 places AIDS prevention and treatment into the input framework discussed in the previous section. Current preventive efforts, while limited to behavioral interventions and use of condoms, are effective. Such preventive efforts do not require sophisticated facilities, personnel, technology or intensive nursing requirements. Inter-sectorial collaboration should not be required. However, for economic, political and cultural reasons, the preventive intervention efforts to date have remained inadequate in most non-industrialized countries [40].

Table 9. Summary of key inputs required to address HIV infection and AIDS

\begin{tabular}{lccc}
\hline & Prevention & Treatment & Chronic care \\
\hline Facility & Low & None & Moderate \\
Personnel & Low & Available & High \\
Technology & Low & & High \\
Nursing & Low & & High \\
Intersector. Collab. Required? & No & & \\
\hline
\end{tabular}

Curative options do not exist. There is some evidence that treatment of HIV infected persons before the onset of symptoms can improve quality of life and probably survival. In the United States such treatment averages $\$ 7000$ to $\$ 12,000$ per patient per annum [41]. To place this cost in perspective, the per capita total health expenditure in the 1980 s for India was 
$\$ 12.5$ and for Bangladesh was \$2.81 [38]. Even for a middle income country such as South Africa, such an expenditure for the estimated number of AIDS patients will have exceeded total current annual health expenditure within the next two decades [41].

For most non-industrialized countries, and poorer populations within countries, such palliative treatment will not be affordable. Conversely, some of the consequences of failure to detect and treat early infections, such as tuberculosis, are also unaffordable [41]. Somewhat more modest pre-morbid treatment plans have been developed in some African countries which are far less costly (e.g. range from $\$ 37$ to $\$ 550$ per annum) - but still beyond the means of most non-industrialized nations [41].

To summarize, AIDS has all of the features of a disease that will increase inequity both between children in the nonindustrialized and industrialized world and for the economically and socially disenfranchised, especially those within nonindustrialized countries.

\section{CONCLUSION}

Globally, child health outcomes are improving. However, both between and within nations, these improvements have proportionately favored those populations who are already experiencing higher child survival rates. There are certain identifable populations who almost invariably have not benefitted equally in these global improvements in health outcomes those who are poor, those whose mothers are not educated, and racial or ethnic groups who are not empowered within the society and/or governing structures. There are additional populations who frequently (but not invariably) are at increased risk: girls and the urban poor. The urban poor are a group that have not received ample consideration in projections and planning. Policy planners have perhaps taken too much comfort from those data suggesting that 'urbanization' is good. 'Urbanization' is neither good nor bad - but it certainly can have devastating effects on select population groups.

As mortality rates decrease, the absolute and relative rates of the underlying conditions also change. There are theoretic reasons for and empiric evidence of increased costs associated with additional improvements in health outcomes as mortality 
rates decrease. Among the industrialized countries both the absolute and the relative government expenditures for health have been increasing, whereas among the non-industrialized countries the trend is for decreasing proportionate expenditure for health. This trend does not bode well for the ability of the nonindustrialized countries to sustain improvements in health outcomes.

The AIDS pandemic further diminishes prospects for equitable improvement. Globally health outcomes are likely to deteriorate, particularly among those who are already disenfranchised.

\section{Increasing equity in the future}

This is not a comforting picture, but nor is it appropriate - or defensible - to complacently accept a future of sustained or exaggerated inequity. Options and opportunities to potentially increase equity do exist and should be aggressively pursued.

Urbanization. It will be essential to delineate aspects of the urbanization process that are intervenable and that, in the absence of intervention, could reduce equity. An integrated approach to planning for housing, environment and sanitation, and health efforts is essential. An integrated perspective on urban employment, child care and education will be essential lest children suffer from parental attempts to achieve economic prosperity.

Disease Prevention. Historically, physicians have been strong advocates of preventive measures for diseases that are currently important and where these measures rely on biomedical interventions such as vaccines. However, physician advocacy has been less impressive regarding diseases that might occur in the future, particularly if there are no bio-technical struts to rely on.

Already in some non-industrialized countries - and soon in many - diseases for which curative measures do not exist or are unaffordable will predominate as the major causes of morbidity and mortality. Rather than waiting for the further emergence of these conditions, preventive efforts should be initiated now. Physicians and public health personnel must abjure the perspective that prevention that is behaviorally based is not as real as prevention that is vaccine - or biomedically based. At 
the same time, behavioral interventions should be subjected to the same degree of scientific scrutiny as biomedical interventions.

Continued investment in maternal education. The influence of maternal education on health outcomes is so powerful that female education should be conceptualized as a primary health intervention.

Loan repayment. Finally, industrialized countries must rethink policies on repayment of loans by non-industrialized countries. More flexible options - options that allow for debt forgiveness by internal reinvestment which mandate targeting of resources so as to increase equity or options investing in the development of lower cost technologies within non-industrialized countries to increase access - might help forestall growing relative inequity between these countries and ours. Monies might be invested into substantially enhanced prevention programs for vulnerable populations.

Acknowledgements - I wish to thank Anna Gadomski, Howard Dubowitz and other faculty members in the Division of General Pediatrics for their helpful comments on earlier drafts of this manuscript. I thank Juanita Morris, Jan Roberts and Yolanda Davis for help in preparing the manuscript.

\section{REFERENCES}

1. Gadomski A. M., Black R. E. and Mosley W. H. Constraints to the potential impact of the direct interventions for child survival in developing countries. Health Policy Planning 5, 235-245, 1990.

2. Jamison D.T. and Mosley W. H. Disease control priorities in developing countries: health policy responses to epidemiological change. Am. J. Public Hlth 18, 15-22, 1991.

3. Mertz R. J., Parker A.L. and Halpin G. J. Pregnancy-related mortality in New Jersey, 1977-1989. Am. J. Public Hlth 82, 1085-1088, 1992.

4. Rawlings J.S. and Weir M. R. Race-and-rank-specific infant mortality in a U.S. military population. Am. J. Dis. Children 146, 313-316, 1992.

5. Daniels N. Rights to health care and distributive justice: programmatic worries. J. Med. Phil. 21, 174-191, 1979. 
6. Roemer M. I. and Roemer R. Global health, national development, and the role of government. Am J. Public Hlth 80, 1188-1192, 1990.

7. UNICEF. State of the World's Children, 1991.

8. World Bank. World Development Report 1989. Oxford University Press, Oxford, 1989.

9. Wilkinson R. G. Income distribution and life expectancy. $B r$. Med. J. 304, 165-168 1992.

10. Task Force for Child Survival. Protecting the World's Children: An Agenda for the 1990's. WHO, Geneva, 1988.

11. Williams B. T. Assessing the health impact of urbanization. World Hlth Statistics Qrtly 43, 145-152, 1990.

12. Harpham T., Lusty T. and Vaughan P. In the Shadow of the City: Community Health and the Urban Poor. Oxford University Press, Oxford, 1988.

13. Bhattacharya Sb. N., Srivastava Sv. K. and Lamba Si. M.S. Some sex differentials of infant mortality in rural areas. J. Family Welfare 34-43, 1981.

14. Kielman A. A., Taylor C. E., DeSweener C., Uberoi I. S., Takulia H. S., Masih N. and Vohra S. The Narangwal experiment on interactions of nutrition and infections: II: Morbidity and mortality effects. Ind. J. Med. Res 68, 21-41, 1978.

15. Bhandari B., Mandowara S. L., Agarwal H. R. and Jagdev D. K. High infant mortality in rural areas of Rajasthan: an analysis based on prospective study. Ind. Pediat. 25, 510-514, 1988.

16. Rip M. R., Keen C. S. and Woods D. L. Intraurban variations of neonatal and post-neonatal mortality in a developing city. Soc. Sci. Med. 25, 889-894, 1987.

17.Nelson M. D. Socioeconomic status and childhood mortality in North Carolina. Am. J Public Hlth 82, 1131-1133, 1992.

18. Kaiser Family Foundation. Changing Health in South Africa. Henry J. Kaiser Family Foundation, Menlo Park, CA, 1991.

19. Fosu G. B. Access to health care in urban areas of developing societies. J. Hlth Soc. Behav. 30, 398-411, 1989.

20. Cohen A. Urban unfinished business. J. Public Hlth Policy SUMmer, 214-221, 1989.

21. Rhode J. E. Why the other half dies: the science and politics of child mortality in the third world. Assignment Children 61/62, 35-67, 1983. 
22. Stanton B., Clemens J., Azia K. M. A. and Rahman M. Comparability of responses to 24 hour recall and knowledgeattitude-practice questionnaire and direct observations in water and sanitation studies. Bull. World Hlth Organ. 65, 217-222, 1987.

23. Richardson J. J. H., Hayden-Smith S., Bokkenheuser V. and Koornhof J. H. Salmonellae and shigellae in Bantu children consuming drinking water of improved quality. South African Med. J. JANUARY, 46-49, 1968.

24. Benyoussef A., Cutler V. L., Baylet R., Collomb H. and Drop S. Santé, migration et urbanization; une étude collective au Sénégal. Bull. World Hlth Organ. 49, 517-537, 1973.

25. Patel R. B. Care of low birth weight babies in slums. Ind. J. Pediat. 56, 231-237, 1989.

26. Nelson V. and Mandl P. E. Peri-urban malnutrition. A neglected problem. Assignment Children 43, 25-46, 1978.

27. Blumberg R. L. Income under female versus male control. J. Family Issues 9, 51-84, 1988.

28. Engle P. Child care strategies of working and non-working women in rural and urban Guatemala. In Women, Work, and Child Welfare in the Third World (Edited by Leslie J. and Paolisso M.). Am. Assoc. Advancement Sci. Selected Symp. $101,1989$.

29. Cleland J. and Ginneken J. V. The effect of maternal schooling on childhood mortality: the search for an explanation. Soc. Sci. Med. 27, 1357-1568, 1988.

30. Caldwell J. C. Education as a factor in mortality decline: an examination of Nigerian data. Population Studies 33, 395414, 1979.

31. Lindenbaum S., Chakradorty M. and Elias M. The influence of maternal education on infant and child mortality in Bangladesh. Int. Center Diarrheal Disease Res. Bangladesh. Special Publication No. 23, 1985.

32. Chen L. C., Huq E. and D'Souza S. Sex bias in the family allocation of food and health care in rural Bangladesh. Population Dev. Rev. 7, 147-163, 1981.

33. Hirshchorn N., Grabowsky M., Houston R. and Steinglass R. Infant mortality rates and cause attributable profiles: some implications for primary health care design. In Child Survival Programs: Issues for the 1990's. The John Hopkins University School of Hygiene and Public Heath Institute for International Programs (Eds). Seminar Report, 1990; pp. 157-168. 
34. Lopez A. D. Cause of death: an assessment of global patterns of mortality around 1985. World Hlth Statistics 43, 91104, 1990.

35. Warner K. E. Tobacco taxation as health policy in the third world. Am. J. Public Hlth 80, 529-531, 1990.

36. D'Souza S. The assessment of preventable infant and child deaths in developing countries: some applications of a new index. World Hlth Statistics Qrtly 42, 16-25, 1989.

37. Stanton B. and Wouters A.M. Guidelines for pragmatic assessment for health planning in developing countries. Hlth Policy 21, 187-209, 1992.

38. World Bank. Improving the Health of the Poor in Asia: Delivery of Public Services. World Bank, Report No. 10260ASIA Washington, DC, 1992.

39. Quinn T. C., Ruff A. and Halsey N. Pediatric acquired immunodeficiency syndrome: special considerations for developing nations. Pediatric human immunodeficiency virus infections. Pediat. Infectious Dis. J. 11, 588-668, 1992.

40. Preble A. A. Impact of HIV/AIDS on African children. Soc. Sci. Med. 31, 671-680, 1990.

41. Doyle P. The impact of AIDS on the South African population. In AIDS in South Africa: The Demographic and Economic Implications. Center for the Study of Health Policy Research, University of Witwatersrand, Johannesburg, No. 23, 1991. 
